\title{
Apagamento do rótico em coda no português santomense e no português principense
}

\section{Rhotic Deletion in Coda in Santomean Portuguese and in Princepean Portuguese}

\author{
Nancy Mendes Torres Vieira [nancy.vieira@usp.br] \\ Universidade de São Paulo, Brasil
}

Amanda Macedo Balduino [amanda.m_b@hotmail.com]

Universidade de São Paulo, Brasil

\begin{abstract}
RESUMO
O objetivo deste artigo é examinar o apagamento do rótico em coda no português de São Tomé (PST) e no português do Príncipe (PP). Para análise desse fenômeno, nos pautamos na Sociolinguística Variacionista e os dados foram modelados por uma regressão logística mista. Investigamos a influência de variáveis previsoras fixas sociais (Variedade do Português, Gênero, Faixa Etária e Nível de Escolaridade) e estruturais (Posição do Segmento, Classe Gramatical, Tonicidade e Contexto Fonológico Precedente), além das variáveis aleatórias: Informante e Item lexical. Com base em um corpus de 2387 ocorrências, constatamos um índice de apagamento do rótico de $54,7 \%$, sendo a maior porcentagem de apagamento $(77,3 \%)$ verificada em coda final (P.R. 0,75). Apesar de o PST e o PP estarem circunscritos a contextos linguísticos distintos, a Variedade do português não foi relevante para o apagamento do rótico em coda, inclusive, não houve diferença significativa entre os índices de apagamento no PST $(53,4 \%)$ e no PP (55,9\%).
\end{abstract}

\section{Palavras-Chave}

Português santomense; Português principense; apagamento do rótico em coda; variáveis sociais e estruturais; contato linguístico

\footnotetext{
Abstract

This paper discusses the rhotic deletion in coda in Santomense Portuguese (PST) and in Princepense Portuguese (PP). Based on the theoretical and methodological principles of Variationist Sociolinguistics, we adopeted a mixed effect modeling. We investigated the influence of fixed social variables predictors (variety of Portuguese, Gender, Age and Education Level) and linguistic variables (Segment Position, Grammatical Class, Tonicity, and Previous Phonological Context), in addition to the random variables: Informant and Lexical Item. Based on a corpus composed of 2387 occurrences, we verified r-deletion in $54.7 \%$ of the data. The highest rate of deletion (77.3\%) was verified in final codas (P.R. 0.75). Although PST and PP are in different linguistic ecologies, the Portuguese Variety was not relevant to the r-deletion in coda: there was no difference between deletion rates in PST (53.4\%) and PP (55.9\%).
} 


\section{KEYWORDS}

Santomense Portuguese; Princepense Portuguese; rhotic deletion in coda; social and structural variables; language contact

RECEBIDO 2021-06-30; ACEITE 2021-09-08

Agradecemos à Fundação de Amparo à Pesquisa do Estado de São Paulo (FAPESP) pelo financiamento que permitiu a condução dessa pesquisa e elaboração deste artigo: processos 2015/25332-1 e 2017/26595-1

\section{Introdução}

O propósito deste artigo é analisar o apagamento do rótico em coda silábica no português santomense (PST) e no português principense (PP) a partir dos pressupostos da Sociolinguística Variacionista (Weinreich et al. 1968; Labov 1972, 1994, 2001), a fim de verificar: (i) a influência de variáveis previsoras sociais e estruturais sobre a ocorrência desse fenômeno e (ii) se há diferença significativa entre o PST e o PP quanto à sua implementação, haja vista o contexto linguístico distinto onde tais variedades emergiram e são empregadas. Para tanto empregamos uma modelagem estatística denominada regressão logística mista, na qual incluímos a variedade do português (PST e PP) como uma variável previsora. Ademais, consideramos, também, na modelagem, o efeito das variáveis aleatórias: Informante e Item lexical.

O PST e o PP são variedades do português empregadas em São Tomé e Príncipe (STP), um país da Costa Oeste Africana, no Golfo da Guiné, cuja única língua oficial é o português. No arquipélago, apesar de o português figurar como única língua oficial, também são empregadas outras línguas como o santome, o angolar e o lung'Ie, línguas filhas do Proto-crioulo do Golfo da Guiné (PGG), uma língua autóctone que emergiu no século XV, na ilha de São Tomé, e depois foi realocada, pela mudança de grupos de falantes, a diferentes regiões do arquipélago, como a ilha do Príncipe (lung'Ie) e o interior da ilha de São Tomé, na região dos Angolares (angolar) (Bandeira 2017). Além do mais, há também o kabuverdianu, uma língua transplantada de Cabo Verde a STP entre os séculos XIX e XX, que integra a ecologia linguística de STP, até hoje, como língua materna de grande parte da comunidade de contratados e seus descendentes (Agostinho 2015; Araujo 2020; Bandeira 2017; Hagemeijer 2018; Agostinho et al. 2020; Freitas et al. 2021).

Tendo em vista esse cenário multilíngue de STP, nota-se que, apesar de o PST e o PP terem emergido em um contexto sócio-histórico similar, surgiram e estão em contato com diferentes línguas. O PST, no momento de sua emergência, estava em contato, principalmente, com o santome, já o PP emerge em uma conjuntura de contato com o lung'Ie. Atualmente, a situação de contato também é distinta para ambas as variedades, uma vez que, enquanto o PST e o santome ainda estão em convivência sincrônica (mesmo frente a diminuição do número de pessoas que se autodenominam falantes de santome), entre os falantes do PP e do lung'Ie como L1 não há uma convivência da mesma intensidade e proporção. De acordo com o censo de 2012 (INE 2012), o lung'le é falado por apenas $1 \%$ da população do país, fato reforçado por estudos como o de 
Agostinho (2015), que aponta ser o lung'le empregado apenas por cerca de 200 pessoas na ilha do Príncipe. Para a autora, esses falantes não são monolíngues, possuem nível de competência variado e geralmente já têm mais de sessenta anos (Agostinho 2015: 7), o que dificulta o contato sincrônico entre o PP e o lung'Ie.

Somando-se aos contextos multilíngues diversos nos quais o PST e o PP estão circunscritos, há de ser considerada, também, a silabificação distinta entre as línguas que circulam em STP e que, por isso, podem promover alterações estruturais no PST e no PP. Do mesmo modo que o português brasileiro $(\mathrm{PB})$ e o português europeu (PE), as variedades em evidência licenciam /r, S, N, l/ em coda, ao passo que o santome comporta apenas /N, J/ (Bandeira 2017) e o lung'Ie /N, S, j, w/ (Agostinho 2015). Dessa forma, além de ambas as línguas autóctones não licenciarem o rótico na coda, em comparação com o PST e o PP, elas favorecem a estrutura silábica CV, visto que licenciam um número menor de segmentos consonantais em posição de coda, além do fato de que sílabas CV constituem o padrão mais frequente no santome e no lung'Ie (Ferraz 1979; Maurer 2009; Agostinho 2015; Bandeira 2017). Logo, as diferenças subjacentes às ecologias nas quais o PST e o PP estão inseridos, assim como a silabificação distinta da coda entre as línguas faladas e em contato em STP, podem conduzir a resultados díspares, dentro de uma perspectiva sociolinguística, em relação à ocorrência do apagamento do rótico em coda em tais variedades.

Isso posto, um dos objetivos deste artigo é analisar dados do PST e do PP, verificando se há diferença significativa entre as duas variedades, na implementação da regra de apagamento do rótico em coda. Ademais, nos propomos a analisar esse fenômeno a partir de uma perspectiva que considera a atuação de múltiplos fatores em seu desencadeamento, abarcando aspectos da estrutura do português e variáveis sociais, além de refletir sobre a própria conjuntura de contato linguístico na qual o PST e o PP estão inseridos.

Para tanto, esse artigo está dividido do seguinte modo: na próxima seção discorremos sobre o PST e o PP, abarcando o contexto sócio-histórico de emergência dessas duas variedades da língua portuguesa. Na seção Apagamento do rótico em coda silábica no PST e no PP, tratamos do fenômeno em questão considerando resultados de estudos prévios e os segmentos licenciados em coda no santome e no lung'Ie. Na seção Metodologia apresentamos os métodos de análise acústica e estatística empregados e, na seção Análise e resultados, descrevemos e analisamos os dados. Enfim, na seção final, tecemos as considerações finais.

\section{O Português Santomense e Principense}

Situado no Golfo da Guiné, São Tomé e Príncipe (STP) é um país da Costa Oeste Africana onde o português é a única língua oficial do arquipélago. Todavia, além do português, outras línguas também transitam no arquipélago e compõem a ecologia linguística de STP. Esse é o caso de línguas autóctones como o santome (ISO 639-3: cri), o angolar (ISO 639-3: aoa) e o lung'Ie (ISO 639-3: pre), bem como do kabuverdianu (ISO 639-3: kea), uma língua levada por falantes cabo-verdianos a STP ao longo dos séculos XIX e XX (Agostinho 2015; Araujo 2020; Bandeira 2017; Hagemeijer 2018).

De acordo com o último censo, $98 \%$ da população se autodeclara falante de língua portuguesa (INE, 2012). Ainda que no censo não haja especificação se o português é falado como língua 
materna ou não, Araujo (2020) indica que a adoção do português como língua oficial, a partir de 1975, criou e intensificou os recursos para ascensão da língua portuguesa em território santomense. De acordo com o autor, além de o português deter prestígio socioeconômico e político na sociedade santomense - estatuto herdado do período colonial, quando o português configurava a língua da metrópole apesar de possuir poucos falantes - os fenômenos do século XX tais quais urbanização, escolarização e expansão da mídia contribuíram para a difusão da língua portuguesa pelo país.

A dispersão da língua portuguesa, em STP, se deu não somente em contato com as demais línguas faladas no arquipélago, mas também pela transmissão irregular do português, incialmente uma segunda língua (L2), a qual passou a ser transmitida como língua materna (Lucchesi e Baxter 2009; Gonçalves 2010; Balduino 2018). A população adquiria as línguas autóctones e, tardiamente no período de escolarização, poderia aprender o português como L2. O processo de aprendizagem de uma L2 diferencia-se do processo de aquisição de uma língua materna (L1), podendo envolver uma série de reanálises estruturais, nas quais a L1 tende a interferir constantemente. Em linhas gerais, o falante, ao aprender uma L2, já possui um sistema linguístico consolidado (L1) e, por isso, a língua materna poderia influenciar a construção de um novo sistema linguístico. Desse modo, as versões de uma língua como L2 tendem a ser distintas da própria língua-alvo.

Em STP, diferentes versões do português L2 eram empregadas pelas pessoas mais velhas como input linguístico para aquisição do português como L1 pela população mais jovem. Conscientes do alto status do português na ilha, os falantes não só aprendiam a língua portuguesa como L2, como também passaram a transmiti-la para as novas gerações, arrefecendo ou mesmo excluindo desse processo as línguas autóctones, pois temiam que o emprego destas, como input, poderia de algum modo, atrapalhar a aquisição do português (Agostinho 2015: 07). Atualmente, há diferentes variedades da língua portuguesa empregadas em STP que possuem características próprias (Balduino 2018). Neste artigo, trabalharemos com duas variedades urbanas distintas: o português santomense (PST) falado na cidade de São Tomé e o português principense (PP), empregado na cidade de Santo Antônio do Príncipe.

Essas variedades, apesar de emergirem em um contexto sócio-histórico similar, estão em contato com diferentes línguas. O PST, por exemplo, no momento de sua emergência, estava em contato, principalmente, como o santome. O PP, de outro modo, com o lung'Ie. Atualmente, a situação de contato também é distinta para ambas as variedades, visto que, enquanto esta é, em certa medida, ainda mantida entre o PST e o santome, a convivência sincrônica entre os falantes do PP e do lung'le como L1 não é mais recorrente. Isso fica ainda mais evidente ao compararmos os dados do censo de 2001 e 2012, no gráfico 1, extraídos do INE.

De acordo com os dados do INE de 2001 e 2012, notamos um decréscimo no uso do santome e do lung'Ie, sendo essa queda mais abrupta para o santome. Conforme os dados de 2012, o lung'le é falado por $1 \%$ da população de STP, enquanto o santome é falado por 33,6\%, percentuais abaixo do censo de 2001, bem como em relação aos valores do português, língua falada por 98,4\% das pessoas de STP (INE 2012).

Esses valores atribuídos pelo censo, no entanto, devem ser reexaminados a partir da distribuição demográfica do arquipélago e da implementação de políticas linguísticas recentes. Em relação aos falantes de lung'Ie, por exemplo, os dados dos censos devem ser relativizados ao número de habitantes do Príncipe. A população do Príncipe equivale a $4 \%$ da população total e, por isso, 
INE (2001-2012)

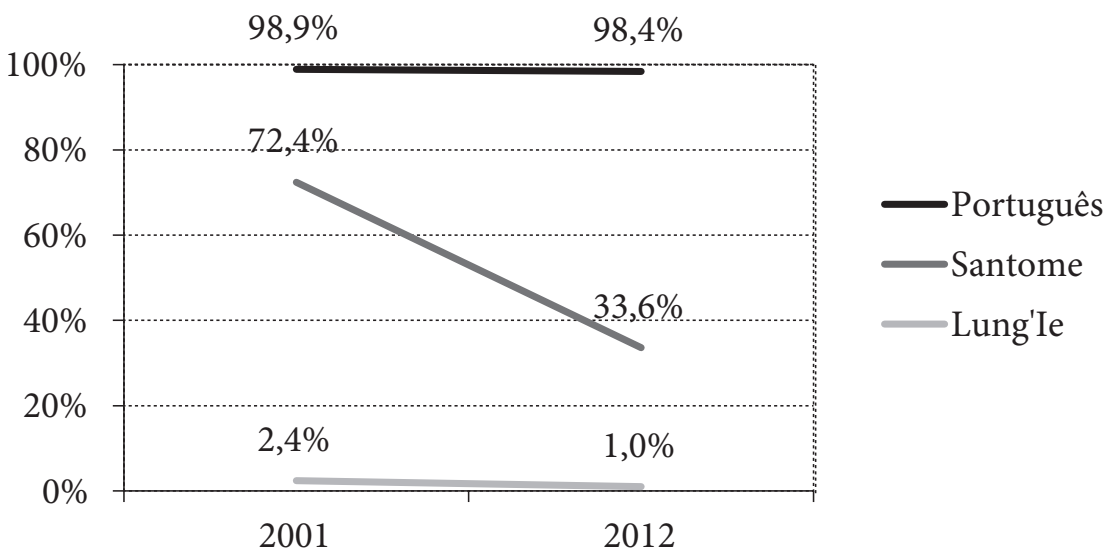

Gráfico 1: Dados percentuais do INE (2001 e 2012)

o número de falantes de lung'Ie, em relação a STP, já seria naturalmente menor contraposto ao português, língua de São Tomé, onde está concentrado o maior contingente populacional do país, e da própria ilha do Príncipe. Além do mais, Agostinho et al. (2016) apontam para um processo de revitalização da língua, visto que o lung'Ie encontra-se em perigo de extinção (Agostinho 2015). Dessa maneira, é perceptível uma preocupação do Governo Regional do Príncipe em promover a cultura lung'Ie, seja mediante a mídia, como no programa Palixa na lung'Ie, transmitido semanalmente (Agostinho et al. 2016), seja por meio de seu ensino, recentemente incorporado aos primeiros anos de escolarização do Príncipe. De acordo com Agostinho et al. (2016: 597), a disciplina de lung'Ie era oferecida, incialmente, de modo optativo da pré-escola até a $11^{\text {a }}$ classe e, a partir de 2016, compulsoriamente a partir da $5^{\text {a }}$ classe.

Como aponta Agostinho (2015), a preocupação de difusão da cultura principense é acompanhada, muitas vezes, pelo interesse de jovens em aprender o lung'Ie, já que o associam à herança étnica-cultural principense. Esse fato reportado por Agostinho (2015) é reforçado nos dados de fala espontânea coletados para condução dessa pesquisa, em 2019. Durante uma das entrevistas conduzidas na ilha do Príncipe, o informante afirma sobre o lung'le:

[...] nossa língua corria risco porque só algumas pessoas, quase nada, na região aqui sabia falar nossa língua [...] então se não tomarmos providência de fazer desenvolver ensinamento dessas línguas então nós corremos o risco de perdermos nossa língua (Homem principense, professor de lung'Ie, 27 anos).

Como pode ser observado, o informante refere-se ao lung'le como "nossa" língua, demarcando uma noção de pertencimento "lung'Ie-principenses" e, consequentemente, associando o lung'Ie à expressão de identidade étnica dos principenses. Destarte, notamos que apesar do uso generalizado do português no Príncipe, o PP emergiu em um contexto diacrônico de contato e, 
atualmente, é empregado em um cenário de implementação de políticas de revitalização linguística do lung'Ie.

Em relação ao santome, os dados do censo apontam que 33,6\% da população se autodenomina falante do santome, sendo esta a língua nacional de STP que possui maior número de falantes. Ainda assim, os dados do gráfico 1 indicam que a despeito do número de falantes do santome em contraposição ao de lung'Ie, cada vez menos pessoas fazem uso desse sistema, ao passo que o português é falado por $98,4 \%$ da população, apresentando um decréscimo de apenas $0,5 \%$ em relação a 2001. Para Afonso (2008) e Agostinho (2015), o domínio do santome é variável, na medida em que diferentes graus de proficiências são observados em São Tomé. Conforme Balduino (2018: 38), mesmo estando em contato com o santome, o domínio que os falantes, principalmente os mais jovens, apresentam deste é instável, limitando-se, muitas vezes, apenas ao uso de vocabulário isolado e à compreensão passiva sem emprego linguístico. Durante diferentes trabalhos de campo na cidade São Tomé, em 2016 e 2019, foram comuns os relatos de falantes mais jovens sobre sua insegurança em empregar as línguas autóctones faladas nas ilhas. Em geral, muitos falantes compreendem o que os mais velhos falam, mas não se servem da língua autóctone em resposta ou entre si. Outros falantes, por sua vez, não se autodenominam falantes das línguas autóctones, embora, em situações específicas, como aquelas em que não querem ser compreendidos por uma terceira pessoa, possam comunicar-se em santome.

A despeito das relações distintas entre os falantes e as línguas autóctones dentro das comunidades de fala contempladas neste estudo, o sistema de uso efetivo nos centros urbanos é o português, o qual além de sofrer constantes interferências por meio do contato linguístico, descende, como pontuado, da transição de L2 para L1. Considerando essas questões subjacentes à emergência e ao uso do PST e do PP, pretendemos, neste artigo, analisar o apagamento do rótico em coda nessas variedades e para tanto, na próxima seção discorremos sobre esse fenômeno nessas duas variedades da língua portuguesa.

\section{Apagamento do rótico em coda silábica no PST e no PP}

A coda, de maneira geral, tem-se mostrado suscetível à variação e apagamentos em diferentes variedades da língua portuguesa (Abaurre e Sândalo 2003; Bisol 1999; Brandão et al. 2003; Callou et al. 1994; Callou et al. 2002; Câmara JR. 1970; Mateus e Rodrigues 2003; Quednau 1993). O apagamento de codas pode ocorrer tanto em PB quanto em PE, entretanto, é mais recorrente em PB (Brandão et al. 2003; Callou e Serra 2012; Oliveira 2018; Rodrigues 2012; Serra e Callou 2015) o que é fundamentado pelo fato de que o PE é uma modalidade de reforço consonântico, enquanto o PB tende a reforçar seu quadro vocálico (Brandão et al. 2003: 14). Em relação a variedades africanas da língua portuguesa, como o Português Angolano (Coelho e Teixeira 2010; Simbo 2016) e o Português Moçambicano (PM) (Brandão 2018; Brandão e De Paula 2018; 2019a, 2019b; Cordeiro 2020), o fenômeno também é reportado, com destaque para o apagamento do rótico.

Nas variedades de STP, notamos que o rótico, em posição de coda, apresenta não somente grande variabilidade, mas possui índices expressivos de apagamento no PST (Brandão et al. 2017; Brandão e De Paula 2018; Brandão 2018; Bouchard 2017; Cordeiro 2020; Vieira e Balduino 2020; 2021) e no PP (Balduino 2019; Balduino et al. 2020). Brandão et al. (2017) e Brandão e De Paula 
(2018a), com base em um corpus coletado em 2009, analisam o rótico em contextos pré-vocálico e pós-vocálico, no PST, observando índices de apagamento do rótico, em coda medial, de 4,4\% e, em coda final, de 44,7\%. O nível de escolaridade dos informantes foi a variável mais significativa na análise do apagamento do rótico nas posições medial e final, com os falantes menos escolarizados favorecendo o apagamento.

Os resultados para a coda final são reiterados nos trabalhos de Brandão (2018) e Cordeiro (2020) os quais estudam o fenômeno a partir do mesmo corpus. Bouchard (2017), por seu turno, ao investigar a emergência da variedade santomense do português, com foco nos róticos e na expressão do pronome sujeito, constata um índice de apagamento do rótico de $14,3 \%$ em coda medial e 79,4\% em coda final, com o maior índice sendo verificado em itens verbais.

Balduino et al. (2020), ao analisar fenômenos cujo domínio é a coda no PST e no PP, indicam que o índice de apagamento do rótico é de $57,4 \%$ para o PST e de 57,9\% para o PP. As autoras, focando sua análise apenas em variáveis estruturais, a saber: a classe gramatical (verbo e não-verbo), a tonicidade da sílaba (átona e tônica), a posição do segmento na palavra morfológica (final e medial), e o contexto fonológico precedente ([a, $\varepsilon, \mathrm{o}, \mathrm{i}, \mathrm{e}, \mathrm{o}, \mathrm{u}]$ e a coda /N/) (Balduino et al. 2020: 5 ) indicam que o apagamento é favorecido em posição final e em itens verbais.

Vieira e Balduino (2021), de outro modo, examinam o apagamento do rótico no PST considerando variáveis sociais (Sexo, Faixa Etária e Grau de Escolaridade) e estruturais (Classe Gramatical, Tonicidade, Posição do Segmento e Contexto Fonológico Precedente) verificando que (i) o índice de apagamento do rótico foi de 56,53\% e (ii) a variável posição do segmento foi a mais significativa para o fenômeno. $\mathrm{Na}$ análise do fenômeno em coda medial, o índice de apagamento foi de $32,6 \%$ e o fenômeno foi favorecido por informantes com o menor nível de escolaridade e do sexo feminino. Já em coda final, o índice foi de 77,5\% e os falantes menos escolarizados e mais jovens foram os mais propensos ao apagamento, além disso, a classe verbal se mostrou favorecedora do processo.

Embora em Balduino et al. (2020) o apagamento do rótico seja analisado no PST e no PP, realizando uma análise contrastiva entre as duas variedades, o trabalho não considera variáveis sociais e, como o estudo de Vieira e Balduino (2021), emprega uma modelagem estatística que não inclui variáveis aleatórias. Neste estudo, portanto, propomos uma análise dos dados do PST e do PP os quais foram submetidos a uma modelagem estatística de regressão logística mista que inclui, além das variáveis fixas estruturais e sociais, variáveis aleatórias (Item lexical e Informante). Ademais, em vez de analisarmos os dados das duas variedades separadamente, optamos por realizar uma análise unificada, na qual a variedade do português é uma variável previsora.

Considerar a variedade do português (PST e PP) como uma variável previsora se justifica pelo contexto linguístico distinto onde tais variedades emergiram e são faladas, há de ser considerado que o santome, em contato, sobretudo com o PST, e o lung'Ie, em contato com o PP, apresentam tratamentos distintos ao rótico - segmento alvo deste estudo. O lung'Ie possui, em seu quadro consonantal, uma vibrante alveolar (Agostinho 2015: 24), ao passo que, no santome, não há róticos (Bandeira 2017).

Conforme Bandeira (2017), o lung'Ie é a única língua-filha do PGG que apresenta uma vibrante /r/. Para a autora, a existência da vibrante no quadro sincrônico da língua foi influenciada não só pelo português, língua lexificadora, mas também pelas línguas edóides, que também possuíam o rótico. Todavia, a despeito de o rótico configurar um elemento comum nas fonologias do lung'Ie 
e do PP - e distinta entre o santome e o PST - a distribuição desse segmento, em relação à coda, não é a mesma entre o PP e o lung'Ie.

No PP, o rótico pode ocupar a primeira e a segunda posição do onset em início e meio de palavra, como em rato ['ra.to] / caro ['ka.ro] e prato ['pra.to] / compra ['kõ.pre], além da coda como em certa ['ser.te] (Balduino 2020; Balduino et al. 2020; Balduino, em preparação). Já em lung’le, o rótico ocorre apenas na primeira posição do onset em início e meio de palavra, mas nunca como coda ou como segundo elemento de um onset complexo (Agostinho 2015; Bandeira 2017). Logo, a despeito de o lung'le e o PP licenciarem o rótico em seus quadros consonantais, ambas línguas apresentam comportamento fonotático distinto em relação à coda.

O PST e o PP, a exemplo do PB e do PE, são variedades que comportam /r, S, N, 1/ em coda, ao passo que o santome licencia apenas /N, J/ (Bandeira 2017), conforme exemplificado em (1). Já o lung'Te licencia /N, S, G/, sendo que G corresponde a um glide /j, w/ (Agostinho 2015) como indicado em (2). Esses glides, em coda silábica, no lung’Ie, formam ditongos ${ }^{1}$, enquanto no santome não há esse tipo de estrutura.

(1) Preenchimento da coda silábica em santome (Bandeira 2017: 169-170):

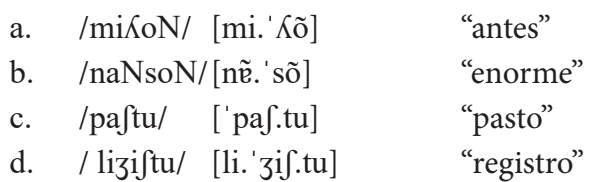

(2) Preenchimento da coda silábica em lung'Ie (Agostinho 2015: 59-89):

a. /oleN/ [o.'lẽ] "além"

b. /goSto/ ['gof.to] “ felicidade”

c. /babew/ [ba.'bew] "barbeiro"

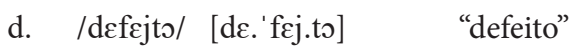

Além de o santome e o lung'Ie não licenciarem o rótico na coda, é perceptível, em contraponto ao PST e ao PP, um favorecimento de sílabas CV nas línguas autóctones de STP, dado que o número de segmentos consonantais permitidos em coda no santome e no lung'Ie é menor. Esse fato é reforçado por Agostinho (2015) que, a partir de um corpus de aproximadamente 4.000 palavras, indica que, em lung'Ie, 76\% das sílabas são CV, sugerindo que o preenchimento em coda é uma estrutura marcada nesta língua.

Neste artigo, um dos propósitos é, justamente, analisar dados do PST e do PP de modo a verificar se há diferença significativa entre as variedades, no que se refere ao apagamento do rótico em coda, já que as duas variedades convivem em contextos linguísticos singulares. Isso posto, na seção, a seguir, apresentamos a metodologia.

1 Em português, um ditongo pode ser entendido como o encontro tautossilábico de uma vogal e um glide numa mesma sílaba, havendo a possibilidade de o glide ser caracterizado como uma vogal sem proeminência na sílaba (Vieira, em preparação). No lung'Ie, no entanto, o glide possui, reconhecidamente, valor consonantal (Agostinho 2015: 75). 


\section{Metodologia}

O presente estudo está baseado nos pressupostos da Sociolinguística Variacionista, desenvolvida por Weinreich et al. (1968) e Labov $(1972,1994,2001)$. A análise do apagamento do rótico em coda no PST e no PP foi realizada a partir de dados de um corpus coletado em São Tomé e Príncipe, constituído por entrevistas de fala espontânea gravadas em 2016 (Agostinho e Balduino 2016) e 2019 (Balduino 2019).

Nesta análise, trabalhamos com 18 entrevistas, sendo 9 para o PST e 9 para o PP. Cada entrevista tem uma duração de, aproximadamente, 60 minutos, porém descartamos os 15 primeiros minutos, a fim de examinarmos uma produção mais próxima à fala vernacular dos informantes. No caso do PST, foram entrevistados quatro homens e cinco mulheres, com idades entre 18 e 52 anos, todos naturais e habitantes da ilha de São Tomé. Quanto ao PP, os informantes foram cinco homens e quatro mulheres, com idades variando entre 22 e 50 anos, todos naturais da ilha do Príncipe $^{2}$. Em ambas as variedades do português, os informantes tinham o português como língua materna e níveis de escolaridade que variam entre a $4^{\text {a }}$ classe (quatro primeiros anos de escolarização) e o ensino superior ${ }^{3}$.

O corpus é composto por ocorrências de palavras com rótico em coda, sendo que, em cada entrevista, não consideramos mais do que seis realizações para uma mesma palavra. Dessa forma, registramos as possíveis realizações de um mesmo item lexical - uma vez que, um mesmo falante pode pronunciar uma mesma palavra de formas distintas - ao mesmo tempo em que restringimos o número de ocorrências de cada item lexical, reduzindo a possibilidade de obtermos o corpus enviesado, posto que esse método limita a influência de palavras de alta frequência que podem não representar o fenômeno de maneira efetiva nas variedades em questão, tais como verbos no infinitivo, nos quais a recorrência de apagamentos do rótico poderia ser numerosa, já que a estrutura dessa classe gramatical constitui contexto propício para o fenômeno. Assim foram contabilizadas 2387 ocorrências, constituídas por 655 palavras, sendo 1168 do PST e 1219 do PP.

Cada ocorrência foi submetida a uma análise acústica, a fim de verificarmos o apagamento do rótico em coda nas palavras analisadas. Para isto, utilizamos o Praat $^{4}$ que possibilitou verificar a realização ou ausência do segmento na produção dessas palavras. $\mathrm{O}$ apagamento foi considerado quando não havia qualquer forma espectral que pudesse ser atribuída ao segmento alvo, o qual já havia sido estabelecido, previamente, mediante uma análise de oitiva. Desse modo, operamos com um exame espectral categórico, o qual não considera formas fonéticas gradientes (Meneses 2012).

2 Os falantes não só tinham nascido em STP, como também eram moradores locais. Dentre os falantes do PST, um informante havia passado três meses em Cabo Verde. Já em relação aos participantes falantes do PP, um informante havia passado dois meses em Portugal.

3 Durante a coleta dos dados seguimos os procedimentos éticos, exigidos na realização de pesquisas com seres humanos, a saber: (i) os participantes da pesquisa eram maiores de 18 anos e assinaram um Termo de Consentimento Livre e Esclarecido (TCLE), contendo informações gerais e esclarecimentos sobre a pesquisa, no qual concordaram, de forma consciente, em participar do estudo; (ii) antes da gravação das entrevistas, os participantes da pesquisa, foram informados de que seriam gravados e, durante as entrevistas, demonstraram estar cientes de tal fato, bem como, seu consentimento em participar do estudo; (iii) os nomes dos entrevistados foram omitidos na divulgação de dados do estudo.

4 Software pelo qual é possível acessar informações acústicas do segmento, como a duração, o formato de onda, o espectrograma e, no caso deste estudo, sua ausência (Boersma e Weenink 2020). 


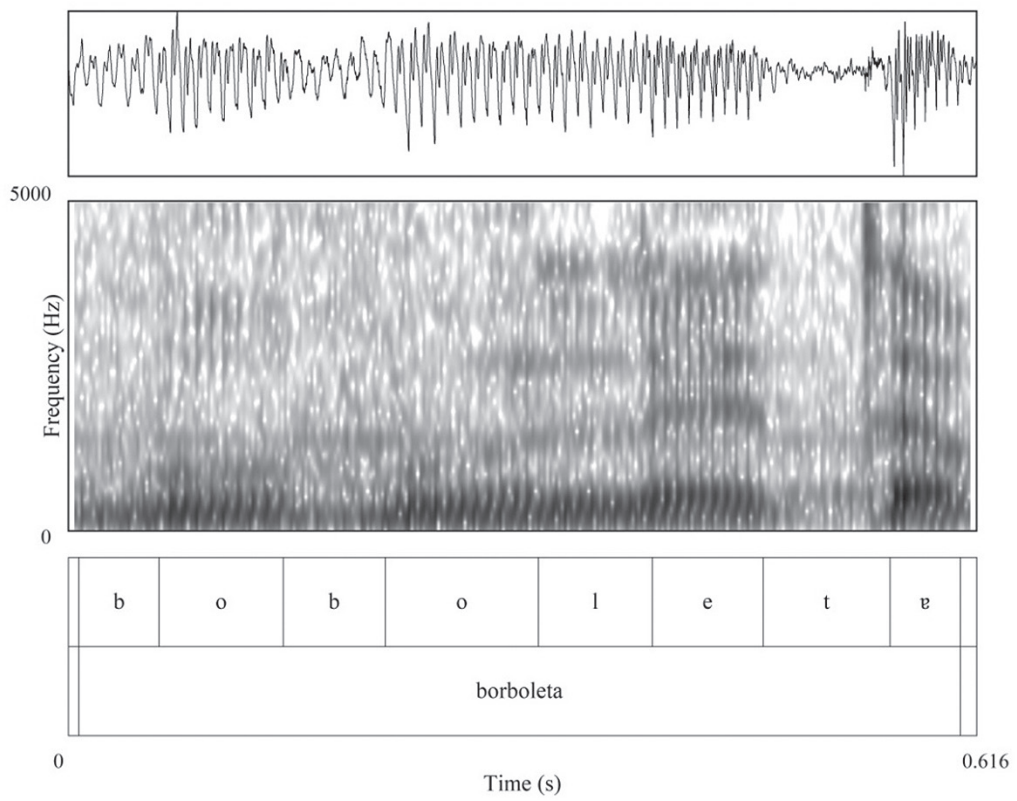

Figura 1: Espectrograma do item lexical borboleta sem realização do rótico em coda medial - PST.

As figuras 1 e 2 correspondem a espectrogramas que exemplificam dados que apresentam o apagamento ou a realização do rótico em coda. Na figura 1, espectrograma de borboleta [bo. bo. 'le.te], notamos que não há a produção do rótico em coda na primeira sílaba.

No segundo espectrograma (figura 2), de outro modo, o rótico [r] é observado na sílaba tônica da palavra certas ['ser.tef], evidenciando os casos nos quais a realização do rótico foi considerado para a análise.

Com os exames espectrais concluídos, realizamos a análise quantitativa dos dados, nomeadamente, uma análise de variável resposta binária - em que a variável resposta é o rótico em coda silábica, o qual pode ser concretizado ou apagado. Os dados foram modelados por uma regressão logística mista, na qual é possível incluir - além das variáveis fixas - variáveis aleatórias. Esse tipo de modelo estatístico verifica o efeito simultâneo de múltiplas variáveis previsoras fixas sobre uma das variantes da variável resposta em análise - neste estudo, o apagamento do rótico em coda - ao mesmo tempo em que considera o efeito das variáveis aleatórias. Nesse modelo as variáveis aleatórias incluídas foram o Informante e o Item lexical, haja vista que tanto a frequência do item lexical quanto o informante podem ser responsáveis por boa parte da variabilidade nos dados (Johnson 2009; Vieira, em preparação). Além disso, verificamos a existência de interações entre as variáveis previsoras fixas controladas, incluindo-as, também, no modelo. A modelagem estatística dos dados foi realizada no Rbrul, um software que pode ser executado no RStudio ou no próprio R.

Um modelo estatístico de efeitos mistos estima o valor do efeito de cada fator de uma variável previsora fixa, considerando, durante os cálculos, o efeito das variáveis aleatórias. Esses valores podem ser calculados em: (i) logodds, numa escala entre $-\infty$ e $\infty$, em que 0 é o ponto neutro, valores positivos 


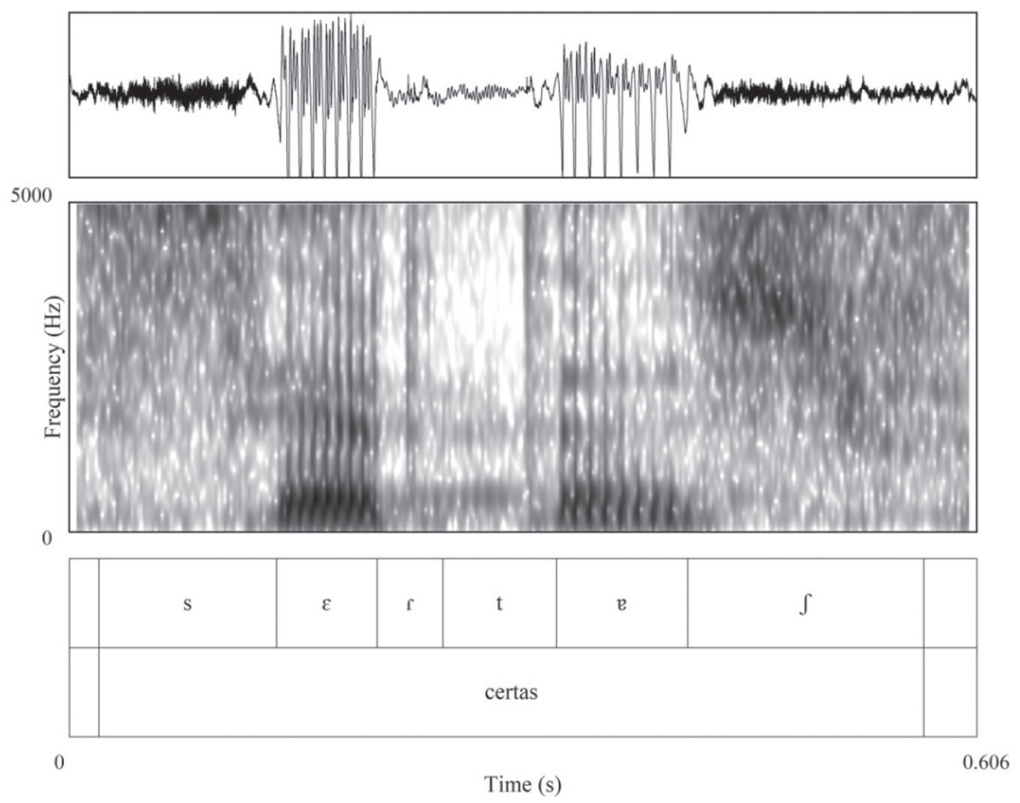

Figura 2: Espectrograma do item lexical certas com realização do rótico em coda medial - PST.

favorecem a variante em análise e valores negativos a desfavorecem; e (ii) em probabilidade, numa escala entre 0 a 1 em que 0 representa uma probabilidade nula de algo ocorrer, 1 representa certeza de que vai ocorrer (100\%) e 0,5 é o ponto neutro, já que equivale a $50 \%$ de certeza de que algo aconteça, dessa maneira, valores superiores a 0,5 indicam uma tendência ao favorecimento da variante em questão e valores inferiores indicam um desfavorecimento (Oushiro 2017; Vieira, em preparação). O Rbrul calcula os valores nessas duas medidas. Neste estudo apresentaremos os valores não apenas em logodds, mas também em probabilidade, haja vista que os valores estimados em probabilidade são amplamente utilizados na Sociolinguística, sendo denominados pesos relativos (P.R.). A tabela 1 mostra a relação entre as medidas de probabilidade e logodds.

\begin{tabular}{ll|c}
\cline { 2 - 3 } & Probabilidade (peso relativo) & Logodds \\
\cline { 2 - 3 } & 0 & $-\infty$ \\
\cline { 2 - 3 } & 0,10 & $-2,20$ \\
\cline { 2 - 3 } & 0,20 & $-1,39$ \\
\hline \multirow{2}{*}{} & 0,30 & $-0,85$ \\
\hline 0,40 & $-0,40$ \\
\hline 0,50 & 0 \\
\hline 0,60 & $+0,40$ \\
\hline 0,70 & $+0,85$ \\
\hline 0,80 & $+1,39$ \\
\hline 0,90 & $+2,2$ \\
\hline 1 & $+\infty$ \\
\hline
\end{tabular}

Tabela 1: Relação entre as medidas de probabilidade e logodds 
O Rbrul também fornece o input, que indica o nível geral de uso de determinado valor da variável resposta em probabilidade e o intercept, valor de referência para o cálculo do efeito dos fatores das variáveis previsoras em logodds, bem como o nível de significância do efeito das variáveis previsoras fixas sobre a variável resposta, também chamado valor- $p$ que é a probabilidade de se observar determinado resultado, ao acaso, se a hipótese nula for verdadeira. Na estatística inferencial, hipótese alternativa $\left(\mathrm{H}_{1}\right)$ é a hipótese que está sendo testada, como, por exemplo, a afirmação de que há uma relação entre uma variável resposta e uma variável previsora, enquanto a hipótese nula $\left(\mathrm{H}_{0}\right)$, é, geralmente formulada como a negação da $\mathrm{H}_{1}$, afirmando que não há relação entre tais variáveis e que a distribuição dos dados é resultante de uma flutuação aleatória e/ou erro de amostragem (Guy e Zilles 2007; Oushiro 2017). Utilizamos, nessa análise, o limite de 0,05, por conseguinte, uma variável só foi considerada significativa para o apagamento do rótico quando apresentou um valor-p igual ou inferior a esse valor.

Incluímos, na modelagem estatística, variáveis previsoras fixas sociais e estruturais. As variáveis sociais incluídas foram: Variedade (PST e PP), Gênero, Faixa Etária e Nível de Escolaridade dos informantes. Trabalhamos com um mesmo número de homens e mulheres (nove homens e nove mulheres) a fim de verificar se há diferenças relacionadas ao Gênero. A variável Faixa Etária foi analisada de duas formas: (i) como variável categórica, com os informantes organizados em três níveis, o primeiro de 18 a 29 anos, o segundo entre 30 e 40 anos e o terceiro entre 41 e 52 anos; e (ii) como variável numérica contínua. O Nível de Escolaridade foi dividido da seguinte forma: da $4^{\mathrm{a}}$ à $9^{\mathrm{a}}$ classe, da $10^{\mathrm{a}}$ à $12^{\mathrm{a}}$ classe e ensino superior (graduação e pós-graduação). A tabela 2 mostra uma estratificação dos informantes conforme a variedade do português empregada, a faixa etária, o gênero e o nível de escolaridade.

\begin{tabular}{|c|c|c|c|c|c|c|c|}
\hline \multirow{2}{*}{$\begin{array}{c}\text { Faixa } \\
\text { Etária }\end{array}$} & \multicolumn{2}{|c|}{ Variedade } & \multicolumn{2}{|c|}{ Gênero } & \multicolumn{3}{|c|}{ Nível de Escolaridade } \\
\cline { 2 - 8 } & PST & PP & Feminino & Masculino & $4^{\text {a à } 9 \text { a classe }}$ & $10^{a}$ à $12^{\text {a }}$ classe & Ensino Superior \\
\hline 18 a 29 & 3 & 3 & 3 & 3 & 2 & 4 & 0 \\
\hline 30 a 40 & 3 & 4 & 3 & 4 & 4 & 0 & 3 \\
\hline 41 a 52 & 3 & 2 & 3 & 2 & 1 & 2 & 2 \\
\hline Totais & 9 & 9 & 9 & 9 & 7 & 6 & 5 \\
\hline
\end{tabular}

Tabela 2: Informantes estratificados

As variáveis previsoras estruturais controladas foram: a Posição do Segmento na palavra morfológica (final e medial) - a qual, em nosso corpus, coincide com a palavra prosódica em 98,7\% (2356/2387) das ocorrências - a Classe Gramatical da palavra (verbo e não-verbo), a Tonicidade da sílaba (átona e tônica) e o Contexto Fonológico Precedente (/a/, /ع/, /e/, /i/, /っ/, /o/ e /u/). 


\section{Análise e Resultados}

Nesta seção analisamos o apagamento do rótico em coda verificando as variáveis sociais e estruturais que influenciam o fenômeno. Foram analisadas 2387 ocorrências - constituídas por 655 palavras - das quais 1168 são do PST e 1219 são do PP, sendo que foram controladas oito variáveis previsoras fixas sendo (i) quatro sociais: Variedade (PST e PP), Gênero, Faixa Etária e Nível de Escolaridade dos informantes e (ii) quatro estruturais: a Posição do Segmento na palavra morfológica, a Classe Gramatical da palavra, a Tonicidade da sílaba e o Contexto Fonológico Precedente.

O apagamento foi constatado em 54,7\% (1306/2387) das ocorrências evidenciando a alta frequência percentual do fenômeno, nas duas variedades do português analisadas e, das oito variáveis testadas, foram selecionadas como significativas para o apagamento do rótico: Posição do Segmento, Classe Gramatical e Nível de Escolaridade dos informantes, conforme a tabela 3. Apesar de o PST e o PP estarem circunscritos a ecologias linguísticas distintas, e, portanto, terem emergido a partir de cenários de contato entre línguas diferentes, a Variedade do português não foi relevante para o apagamento do rótico em coda, inclusive, não houve diferença significativa entre os índices de apagamento no PST e no PP, 53,4\% e 55,9\%, respectivamente.

\begin{tabular}{|c|c|c|c|c|c|}
\hline Variável & Fatores & Apl./N & $\% \mathrm{R}-\varnothing$ & Logodds & P.R. \\
\hline \multirow[t]{3}{*}{ Posição } & Final & $1017 / 1316$ & 77,3 & 1,15 & 0,75 \\
\hline & Medial & $289 / 1071$ & 27,0 & $-1,15$ & 0,25 \\
\hline & & $1306 / 2387$ & & & Range 0,50 \\
\hline \multirow[t]{4}{*}{ Nível de Escolaridade } & $4^{\text {a }}$ à $9^{\mathrm{a}}$ classe & $625 / 906$ & 69,0 & 1,08 & 0,75 \\
\hline & $10^{\mathrm{a}}$ à $12^{\mathrm{a}}$ classe & $445 / 872$ & 51,0 & $-0,16$ & 0,46 \\
\hline & Superior & $236 / 609$ & 38,8 & $-0,91$ & 0,28 \\
\hline & & $1306 / 2387$ & & & Range 0,47 \\
\hline \multirow[t]{3}{*}{ Classe Gramatical } & Verbos & $959 / 1294$ & 74,1 & 0,54 & 0,64 \\
\hline & Não-verbos & $347 / 1093$ & 31,7 & $-0,54$ & 0,36 \\
\hline & & $1306 / 2387$ & & & Range 0,26 \\
\hline
\end{tabular}

Tabela 3: Variáveis atuantes no apagamento do rótico em coda no PST e no PP

$(\mathrm{N}=2387 ; \mathrm{R}-\emptyset=54,7 \%$; Intercept: $-0,08 ;$ Input: 0,48)

A Posição do Segmento foi a variável que exerceu um efeito mais significativo sobre a ocorrência de apagamento do rótico, com um range $^{5}$ de 0,50 entre os pesos relativos. O maior índice de apagamento $(77,3 \%)$ foi verificado quando o rótico está em posição final (logodds: 1,15; P.R. 0,75), enquanto a posição medial desfavoreceu o apagamento (logodds: -1,15; P.R. 0,25), conforme exemplificado em (3). Isso poderia ser, a princípio, associado às ocorrências de verbos no infinitivo, como em (4), contudo a posição final favoreceu o processo não apenas em itens verbais, mas também em itens não-verbais como em (5) (cf. gráfico 2).

5 Diferença entre o menor e o maior peso relativo dos fatores de uma variável. Geralmente, quanto maior o range mais significativa é a variável. 
(3) Posição do rótico:

a. coda final: maior [mar. 'or] [mar.' 'o]

b. coda medial: turma ['tur. me] $~[$ 'tu. me]

(4) Verbos no infinitivo:

a. $\quad$ achar [a.' $\left.\int \mathrm{ar}\right] \sim\left[\mathrm{a}\right.$. ' $\left.\int \mathrm{a}\right]$

b. poder [ро.' 'еке $\sim$ [ро.' de]

c. $\quad$ sair [sa.'ir] [sa.'i]

(5) Itens não-verbais

a. sabor [sa.' 'ьов] [sa.' bo]

b. $\quad$ prazer [pra.'zer] [pra.'ze]

Uma explicação desse resultado pode ser alcançada pelo emprego da Teoria da Hierarquia Prosódica, a partir da qual Callou e Serra (2012), estudam o mesmo fenômeno, apontando que a fronteira de palavra prosódica, em detrimento da fronteira do sintagma fonológico e do sintagma entoacional, é um contexto que favorece o apagamento do rótico - apesar de considerarmos, neste estudo, a palavra morfológica, em nosso corpus esta coincide com a palavra prosódica em 98,7\% dos casos - em itens lexicais como professor, sabor e fazer. O percentual restante $(1,3 \%)$ corresponde a advérbios como normalmente e anteriormente (cf. Ulrich e Schwindt 2018).

No que se refere à Escolaridade, o apagamento do rótico em coda é favorecido por falantes com menor nível de escolaridade (logodds: 1,08; P.R. 0,75) e desfavorecido por aqueles com ensino superior (logodds: -0,91; P.R. 0,28) e ensino médio (logodds: -0,16; P.R. 0,46). Tais resultados apontam, portanto, que indivíduos menos escolarizados apagam o rótico com mais frequência do que os mais escolarizados, o que pode estar relacionado ao fato de que falantes com maior nível de escolaridade tendem a se aproximarem mais da norma prestigiada, nomeadamente, a norma lisboeta da variedade europeia, disseminada pela escola, que, por sua vez, apresenta baixos índices de apagamento do rótico em coda (Brandão et al. 2003; Mateus e Rodrigues 2003). Esse resultado está em consonância com o que foi verificado em estudos prévios sobre o PST como o de Bouchard (2017), Brandão et al. (2017), Brandão e De Paula (2018), Brandão (2018) e Vieira e Balduino (2021).

Quanto à variável Classe Gramatical da palavra, o maior índice de apagamento (74,1\%) ocorre nos itens verbais (logodds: 0,54; P.R. 0,64), em contraponto ao índice verificado nas palavras nãoverbais ((logodds: -0,54; P.R. 0,36), conforme exemplificado em (6) e (7).

(6) Itens verbais

a. coda medial: ferve ['fé.vI] ['fe.vI]

b. coda final: pedir [pe.'dir] [pe.'di]

(7) Itens não-verbais

a. coda medial: parte ['par.tI] ['pa.tI]

b. coda final: lugar [lu.' gar] [lu. 'ga] 
Cruzamento entre as variáveis Posição do Segmento e

Classe Gramatical

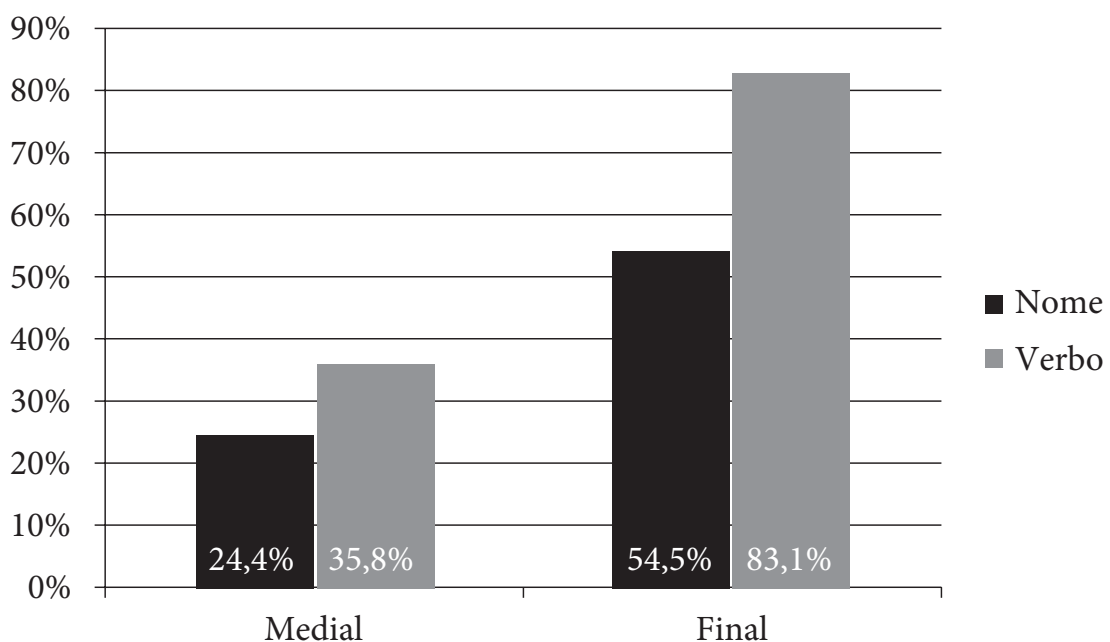

Gráfico 2: Cruzamento das variáveis: Posição do Segmento e Classe Gramatical da palavra

Por fim, a análise estatística, realizada no Rbrul, indicou interações entre as variáveis Posição do Segmento e Classe Gramatical da palavra e, também, entre Nível de Escolaridade dos informantes e Classe Gramatical da palavra. Os gráficos 2 e 3 mostram os cruzamentos dessas variáveis.

O gráfico 2 mostra que o maior índice de apagamento do rótico em coda é verificado em itens verbais quando o rótico está em posição final $(83,1 \%)$, isto é, em verbos no infinitivo, enquanto o menor índice é o dos itens não verbais em posição medial $(24,4 \%)$, corroborando resultados de estudos sobre o mesmo fenômeno no PST (Brandão et al. 2017; Brandão e De Paula 2018; Brandão 2018; Bouchard 2017; e Vieira e Balduino 2021), no PP (Balduino 2019) e, também, no português brasileiro (Callou 1987; Callou et al. 2002; Callou e Serra 2012; Callou et al. 2015; Oliveira 2018; Oushiro e Mendes 2014).

O gráfico 3 indica que, apesar de os maiores índices de apagamento serem verificados nos verbos, quanto maior o nível de escolaridade do informante, menor é o índice de apagamento do rótico em coda, assim o maior índice ocorre entre os falantes menos escolarizados $(85,5 \%)$, evidenciando a relevância das duas variáveis.

Em suma, o apagamento do rótico em coda é influenciado por variáveis sociais e estruturais, sendo muito recorrente nas duas variedades do português analisadas, e tal recorrência, bem como as diferentes possibilidades de realização desse segmento em coda - desde uma vibrante alveolar, passando por sua vocalização, até seu apagamento -, pode ser analisada como um processo de enfraquecimento desse segmento em coda o qual resulta numa simplificação silábica de uma estrutura CVC para uma CV (Callou et al. 2002). Dessa forma, os índices de apagamento no PST $(53,4 \%)$ e no PP $(55,9 \%)$ sugerem, de forma semelhante ao que se observa no PB, uma tendência dessas duas variedades ao padrão silábico CV, estrutura silábica universal (cf. Selkirk 1982; Balduino et al. 2020; Vieira e Balduino 2021). 
Cruzamento entre as variáveis Nível de Escolaridade e

Classe Gramatical

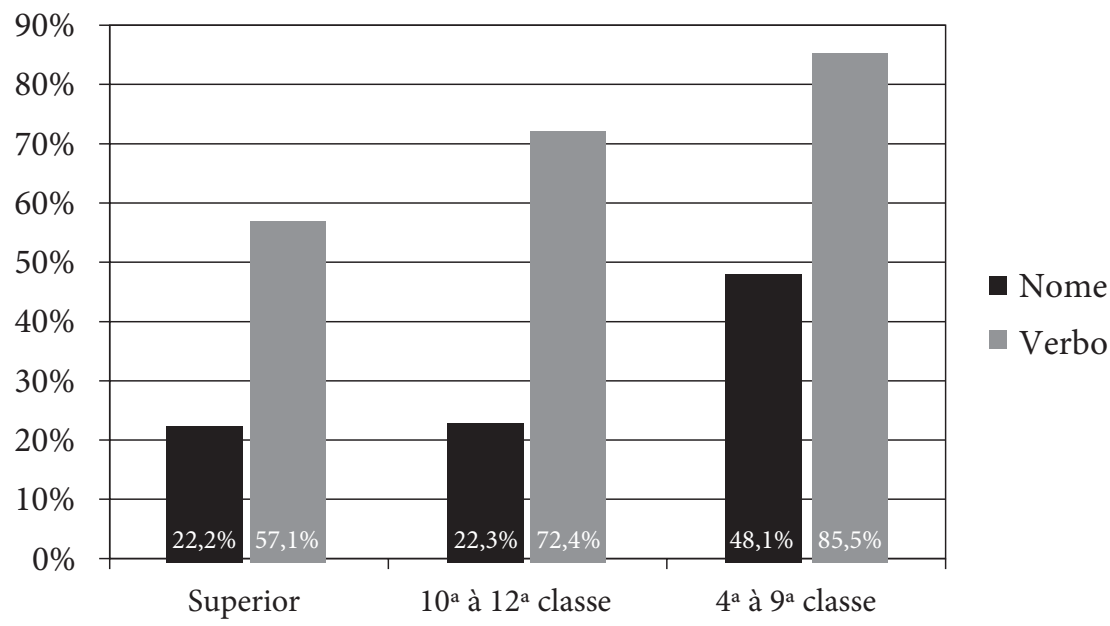

Gráfico 3: Cruzamento das variáveis: Nível de Escolaridade do informante e Classe Gramatical da palavra

Notamos, dessa maneira, que diferentes fatores parecem favorecer o apagamento do rótico em coda no PST e no PP. Além da própria estrutura da língua portuguesa que, como observado em diferentes variedades do português, como o PB, o PE e o PM as quais, apesar de emergentes em contextos singulares e distintos ao PST e ao PP, também comportam o apagamento do rótico nessa posição. Há de ser considerado que, tipologicamente, o apagamento de codas é reportado como um fenômeno recorrente às línguas naturais, visto que a estrutura CVC é, em geral, assinalada como uma estrutura marcada em relação ao template $\mathrm{CV}$, também verificado no PST e no PP.

Apesar de não haver "tipologia neutra”, pois isso depende do quadro teórico no qual a estrutura silábica está inserida (Kiparsky 2018), a sílaba CV, dentro da proposta gerativa, é amplamente reconhecida como sendo a menos marcada (Clements e Keyser 1983). Tal generalização é feita com base na observação de que diversas línguas não permitem codas e, as línguas que as licenciam, também permitem estruturas CV, como é o caso do português. Além do mais, estudos em aquisição da linguagem indicam que a forma CV é, em geral, adquirida antes da forma CVC (Stites et al. 2004). Essa tendência universal é reforçada por trabalhos como o de Selkirk (1982) que aponta ser a coda o elemento mais frágil da estrutura silábica e, por isso, suscetível a apagamentos, e como o de Clements (1990) que propõe ser a estrutura CV a menos marcada.

Assim sendo, o apagamento do rótico no PST e no PP se justificaria, dentre outros fatores, por uma alteração do template CVC para o CV, estrutura menos marcada e observada, outrossim, nas línguas crioulas que convivem com as variedades em questão. Logo, os altos índices de apagamento no PST e no PP também podem estar associados ao ambiente de contato linguístico no qual as duas variedades estão inseridas, posto que tanto o santome com o qual o PST está em contato, 
quanto o lung'Ie, em contato com o PP, não possuem licenciamento do rótico em posição de coda (Agostinho 2015; Bandeira 2017) ${ }^{6}$.

Se concebemos a língua como um organismo que evolui no meio em que está inserido (Mufwene, 2004; Couto, 2009), o favorecimento de traços deve ser interpretado a partir de relações de interação e, desse modo, situações de contato promoveriam uma competição de traços linguísticos de forma que os mais semelhantes, nas línguas em contato, seriam favorecidos, enquanto traços distintos seriam desfavorecidos (Couto 2009; Avelar e Galves 2014) ${ }^{7}$. Destarte, o apagamento do rótico em coda, que resulta numa estrutura silábica CV pode estar relacionado ao fato de o santome e o lung'Ie, além de não licenciarem o rótico em posição de coda, em contraponto ao PST e ao PP, favorecerem sílabas $\mathrm{CV}$, já que o número de segmentos consonantais permitidos em coda nessas duas línguas autóctones é menor do que no PST e no PP (Agostinho 2015; Bandeira 2017).

\section{Considerações Finais}

Os índices consideráveis de apagamento no PST $(53,4 \%)$ e no PP $(55,9 \%)$ são influenciados por variáveis sociais e estruturais: o apagamento do rótico em coda é favorecido em coda final (P.R. 0,75), em itens lexicais verbais (P.R. 0,64) e pelos falantes menos escolarizados (P.R. 0,75). A Variedade do português não foi relevante para o apagamento do rótico em coda, apesar de o PST e o PP terem emergido em cenários de contato entre línguas diferentes e de serem faladas em contextos linguísticos e sociais distintos.

Os altos índices de apagamento no PST e no PP também podem, a princípio, serem explicados por uma alteração do template CVC para o CV, estrutura menos marcada e observada nas línguas crioulas que convivem com as variedades em questão. Esse resultado sugere a existência de uma tendência dessas variedades do português ao padrão silábico CV - ainda que outras estruturas sejam possíveis e produtivas. Por fim, o apagamento pode estar associado ao ambiente de contato linguístico no qual as duas variedades estão inseridas, pois tanto o santome quanto o lung’le não possuem licenciamento do rótico em coda silábica e tendem a favorecer a estrutura CV.

6 Essa hipótese deve ser avaliada, entretanto, tendo em vista outros processos da língua que, em algumas ocasiões, podem apontar para direções opostas, isto é, para a emergência de sílabas complexas como CCCV, CCCVC, entre outras (Balduino 2020).

7 O kabuverdianu é uma língua que também circula em STP e que pode influenciar o fenômeno, porém, neste artigo, não a incorporaremos à discussão. 


\section{Referências bibliográficas}

Abaurre, M. B. M.; \& Sândalo, M. F. S. (2003). Os róticos revisitados. In D. Hora, \& G. Collischonn (Eds.), Teoria Linguística: Fonologia e outros temas (pp.144-180). João Pessoa: Editora Universitária - Universidade Federal da Paraíba.

Afonso, B. (2008). A problemática do bilinguismo e ensino da língua portuguesa em S. Tomé e Príncipe. (Mestrado). Universidade Nova de Lisboa, Lisboa.

Agostinho, A. L. (2015). Fonologia e Método Pedagógico do Lung'ie. (PhD). Universidade de São Paulo, São Paulo.

Agostinho, A. L.; \& Balduino, A. (2016). Trabalho de Campo. Inédito.

Agostinho, A. L.; Bandeira, M.; \& Araujo, G. (2016). O Lung'ie na educação escolar de São Tomé e Príncipe. Trabalhos em Linguística Aplicada, 55, 3, 591-618. https://doi.org/10.1590/010318135164183401

Agostinho, A. L.; Bandeira, M.; \& Freitas, S. (2020). Línguas Crioulas e Lusofonia em São Tomé e Príncipe. In S. I. C. Vasconcelos, \& F. M. Souza (Eds.), Lusofonias em debate (pp. 63-86). São Paulo: Mentes Abertas. Araujo, G. Há uma política linguística para o português em São Tomé e Príncipe? (2020). In S. Souza, \& F. C. Olmo, (Eds.), Línguas em português - A Lusofonia numa visão Crítica (pp. 173-197). Porto: Universidade do Porto Press.

Avelar, Juanito; \& Galves, Charlotte. (2014). O papel das línguas africanas na emergência da gramática do português brasileiro. Linguística: Revista da Associação de Linguística e Filologia da América Latina-ALFAL, 30, 2, 241-288.

Bandeira, M. (2017). Reconstrução fonológica e lexical do protocrioulo do Golfo da Guiné. (PhD). Universidade de São Paulo, São Paulo.

Balduino, A. M. (2018). A nasalidade vocálica no português falado em São Tomé e Príncipe. (Mestrado). Universidade de São Paulo, São Paulo.

. (2019). Trabalho de campo. Inédito.

. (2019). Apagamento de /R/ e /S/ em coda no Português Principense. Papia, 29, 1, 25-39. http://10.0.20.161/zenodo.3924791

- (2020). Templates silábicos no Português do Príncipe: processos em coda e 'prevalência' de sílabas CV. Filologia e Linguística Portuguesa, 22, 2, 247-270. https://doi.org/10.11606/issn.2176-9419. v22i2p247-270

- (Em preparação). Processos Fonológicos no Português de São Tomé e de Santo António do Príncipe. $(\mathrm{PhD})$. Universidade de São Paulo, São Paulo.

Balduino, A. M.; Vieira, N. M. T.; \& Freitas, S. (2020). A coda no Português Santomense (PST) e Principense (PP): aspectos gerais e processos de apagamento. Revista Abralin, 19, 1, 1-26. https://doi.org/10.25189/ rabralin.v19i1.1690

Bisol, L. (1999). A sílaba e seus constituintes. In M. H. M. Neves (Ed.), Gramática do Português culto falado: novos estudos (pp. 701-742). Campinas: Editora da Unicamp.

Bouchard, M. (2017). Linguistic variation and change in the Portuguese of São Tomé. (PhD). New York University, New York.

Boersma, P.; \& Weenink, D. (2020). Praat: doing phonetics by computer (Version 5.3.82). Computer Program. http://www.praat.org

Brandão, S. F. (2018). Apagamento de R em coda externa em duas variedades africanas do português. Diadorim, 20, Especial, 390-408. https://doi.org/10.35520/diadorim.2018.v20n0a23283 
Brandão, S. F.; \& De Paula, A. (2018). Róticos nas variedades santomense e moçambicana do Português. In S. F. Brandão (Ed.), Duas variedades africanas do Português: variáveis fonético-fonológicas e morfossintáticas (pp. 93-118). São Paulo: Blucher.

- (2019a). A variável (R) no Português de Moçambique. Estudo apresentado no XXIX Congresso Internacional de Linguística e Filologia Românicas, Universidade de Copenhague, Copenhague.

- (2019b). Ainda sobre os róticos no Português de Moçambique. In M. M. S. Vieira, \& M. L. Weidemer (Eds.), Dimensões e experiências em Sociolinguística (pp. 211-235). São Paulo: Blucher.

Brandão, S. F.; Mota, M. A.; \& Cunha, C. S. (2003). Um estudo contrastivo entre o português europeu e o português do Brasil: o-R final de vocábulo. In S. F. Brandão, \& M. A. Mota (Eds.), Análise contrastiva de variedades do português: primeiros estudos (pp. 163-180). Rio de Janeiro: In-fólio.

Brandão, S. F.; Pessanha, D. B.; Pontes, S.; \& Corrêa, M. (2017). Róticos na variedade urbana do Português de São Tomé. Papia, 27, 2, 293-315.

Callou, D. M. (1987). Variação e Distribuição da Vibrante Na Fala Culta do Rio de Janeiro. (PhD). Universidade Federal do Rio de Janeiro, Rio de Janeiro.

Callou, D. M.; Leite, Y.; \& Moraes, J. (1994). Variação e diferenciação dialetal: a pronúncia do /r/ no português do Brasil. In I. G. V. Koch (Ed.), Gramática do Português Falado (pp. 465-493). Campinas: Editora da Unicamp/FAPESP.

. (2002). Processo(s) de enfraquecimento consonantal no português do Brasil. In M. B. M. Abaurre, \& A. C. S. Rodrigues (Eds.), Gramática do português falado VIII: novos estudos descritivos (pp. 537555). Campinas: Editora da Unicamp/FAPESP.

Callou, D. M.; \& Serra, C. (2012). Variação do rótico e estrutura prosódica. GELNE, 14, Especial, 41-58.

Callou, D. M.; Serra, C.; \& Cunha, C. (2015). Mudança em curso no português brasileiro: o apagamento do R no dialeto nordestino. Revista Abralin, 14, 1, 195-219. http://dx.doi.org/10.5380/rabl.v14i1.42491

Câmara Jr., J. M. (1970). Estrutura da Língua Portuguesa. Petrópolis: Vozes.

Clements, G. N. (1990). The role of the sonority cycle in core syllabification. In J. Kingston, \& M. Beckman (Eds.), Papers in Laboratory Phonology I (pp. 283-333). Cambridge: Cambridge University Press.

Clements, G. N.; \& Keyser, S. J. (1983). CV Phonology. Cambridge: MIT Press.

Coelho, T. S.; \& Teixeira, E. P. (2010). A variação do /r/ em posição de coda final no português de Angola.

Cordeiro, H. L. R. E. (2020). Uma complementação às análises sobre o cancelamento do rótico em coda externa no português de São Tomé e no português de Moçambique. (Monografia). Universidade Federal do Rio de Janeiro, Rio de Janeiro.

Couto, H. H. (2009). Linguística, ecologia e ecolinguística: contato de línguas. São Paulo: Contexto.

Ferraz, L. (1979). The creole of São Thome. Johannesburg: Witwatersrand University Press.

Freitas, S.; Bandeira, M.; \& Agostinho, A. L. (2021). Cape Verdean Migration to São Tomé and Príncipe: History and Linguistic Effects. Estudo apresentado no Society for Pidgin and Creole Linguistics (SPCL) Winter Meeting.

Gonçalves, R. (2010). Propriedade de Subcategorização verbal no português de S. Tomé. (Mestrado). Universidade de Lisboa, Lisboa.

Guy, G.; \& Zilles, A. (2007). Sociolinguística quantitativa. São Paulo: Parábola Editorial.

Hagemeijer, T. (2018). From creoles to Portuguese: Language shift in São Tomé and Príncipe. In L. López; P. Gonçalves, \& J. Avelar (Eds.), The Portuguese language continuum in Africa and Brazil (pp. 169-184). Amsterdam/Philadelphia: John Benjamins.

INE. (2012). Instituto Nacional de Estatística: São Tomé e Príncipe em números. https://www.ine.st/ 
Johnson, D. E. (2009). Getting off the GoldVarb Standard: Introducing Rbrul for Mixed-Effects Variable Rule Analysis. Language and Linguistics Compass, 31, 1, 359-383.

Kiparsky, P. (2018). Formal and empirical issues in phonological typology. In L. Hyman, \& F. Plank (Eds.), Phonological Typology (pp. 01-20). De Gruyter Mouton.

Labov, W. (1972). Sociolinguistic patterns. Philadelphia: University of Pennsylvania Press. . (1994). Principles of linguistic change: internal factors (vol. 1). Oxford: Blackwell. . (2001). Principles of linguistic change: social factors (vol. 2). Oxford: Blackwell.

Lucchesi, D.; \& Baxter, A. (2009). A transmissão linguística irregular. In D. Lucchesi, A. Baxter, \& I. Ribeiro (Eds.), O Português Afro-Brasileiro (pp. 427-445). Salvador: EDUFBA.

Mateus, M. H. M.; \& Rodrigues, C. (2003). A Vibrante em Coda em Português Europeu. In D. Hora, \& G. Collischonn (Eds.), Teoria Linguística Fonologia e Outros Temas (pp. 181-199). João Pessoa: Ed. Universitária.

Maurer, P. (2009). Principense Grammar texts, and vocabulary of the afro-portuguese creole of the island od Príncipe, Gulf of Guinea. London: Battlebridge Publications.

Meneses, F. O. (2012). As vogais desvozeadas no Português Brasileiro: investigação acústico-articulatória. (Mestrado). Universidade Estatual de Campinas, Campinas.

Mufwene, S. (2004). The Ecology of Language Evolution. Cambridge: Cambridge University Press.

Oliveira, I. C. (2018). Os róticos em coda silábica externa: o interior da região Sul no projeto AliB. (Mestrado). Universidade Federal do Rio de Janeiro, Rio de Janeiro.

Oushiro, L. (2017). Introdução à Estatística para Linguistas, v.1.0.1 (dez/2017). Licença Creative Commons 4.0 Atribuição - Não comercial. https://rpubs.com/oushiro/iel

Oushiro, L.; \& Mendes, R. B. (2014). O apagamento de (-r) em coda nos limites da variação. Veredas Atemática, 18, 2, 251-266.

Quednau, L. (1993). A lateral pós-vocálica no português gaúcho: análise variacionista e representação não linear. (Mestrado). Pontifícia Universidade Católica do Rio Grande do Sul, Porto Alegre.

Rodrigues, M. C. (2012). Todas as codas são frágeis em português europeu? Revista LinguíStica - Revista do Programa de Pós-Graduação em Linguística, Universidade Federal do Rio de Janeiro, 8, 1, 138-149.

Selkirk, E. (1982). The syllable. In H. Hulst, \& N. Smith (Eds.), The Structure of Phonological Representations (pp. 337-383). Dordrecht: Foris.

Serra, C.; \& Callou, D. M. (2015). Prosodic structure, prominence and /r/-deletion in final coda position: Brazilian Portuguese and European Portuguese contrasted. In A. Dominicis (Ed.), pS-prominenceS: Prominences in Linguistics. Proceedings of the International Conference. Department of Human Sciences and Tourism. University of Tuscia (pp. 96-113). Viterbo-Italy: Disucom Press.

Simbo, A. C. (2016). Róticos no Português de Angola-Variante de Cabinda. (Mestrado). Universidade do Porto, Porto.

Stites, J.; Demuth, K.; \& Brown, C. (2004). Markedness vs. Frequency Effects in Coda Acquisition. Providence: Brown University.

Ulrich, C.; \& Schwindt, L. C. (2018). O status morfoprosódico dos sufixos -inho/-zinho, -mente e -íssimo no português brasileiro. DELTA, 34, 2. https://doi.org/10.1590/0102-445030726356878044

Weinreich, U.; Labov, W.; \& Herzog, M. (1968). Empirical foundations for a theory of linguistic change. In W. P. Lehmann, \& Y. Malkiel (Eds.), Directions for historical linguistics (pp. 97-195). Austin: University of Texas Press. 
Vieira, N. M. T.; \& Balduino, A. M. (2020). Apagamento de /R, S, 1/ na coda no português de São Tomé: convergência linguística? Papia, 30, 1, 7-33. http://doi.org/10.5281/zenodo.3926952

- (2021). Apagamento do rótico em coda no português santomense (PST): Uma análise sociolinguística. Revista de Estudos da Linguagem, 29, 3, 2011-2040. http://doi.org/10.17851/2237-2083.29.3.20112040

Vieira, N. M. T. (Em preparação). Monotongação de ditongos orais no português brasileiro: uma revisão sistemática da literatura. (Mestrado). Universidade de São Paulo, São Paulo. 



\section{COMPTES \\ RENDUS}

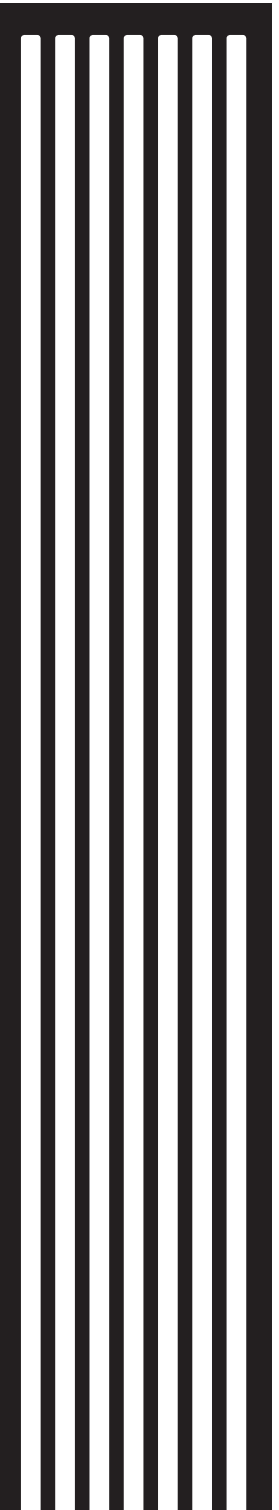


